\title{
Editorial
}

\section{The future of ocean drilling in the Southern Ocean}

$\mathrm{M}$ arine drilling and coring in the high latitudes has had high success in terms of its scientific return. From the early days of the USS Eltanin and Deep Sea Drilling Programme (DSDP) through to the most recent Integrated Ocean Drilling Programme (IODP) expedition 318 to the Wilkes Land margin, drilling and coring on the Antarctic margin has provided a bounty of new information that has caused us to fundamentally rethink our understanding of how global climate and oceanic systems work, and how they interact with plate tectonics.

It is hard to overemphasise the scientific value of drilling at high latitudes. These polar areas experience the most amplified effects of environmental change and are therefore likely to preserve records with the highest amplitude signals from the past. For example, DSDP legs 28 and 29 provided us with a profound insight into global climate history, finding evidence for Antarctic glaciation that long predated the oldest evidence of Cenozoic glaciation in the Northern Hemisphere, and confirming oxygen isotope evidence for global cooling at the Eocene-Oligocene boundary. More recently, the IODP ACEX expedition to the Arctic Ocean has revealed evidence for sub-tropical Eocene warmth and even a period of extreme freshening in the upper waters of the ocean basin. The most recent iteration of global oceanic drilling, the IODP, comes to an end in 2013 and scientists around the world are currently involved in vigorous discussions on what may replace it.

Ocean drilling from floating platforms tends to reach polar waters about once per decade. A recent major meeting at MARUM in Bremen was convened to discuss the successor to IODP (IODP New Ventures in Exploring Scientific Targets, INVEST, September 2009). Antarctic scientists were well represented at this meeting although only a small fraction of the white papers submitted were related to Antarctic drilling. Of course, the direction of ocean science is driven by the community. For example, the INVEST meeting in Bremen identified the Arctic Ocean and the deep biosphere as exploration targets for a future ocean drilling programme. Although it is a challenging task, the Antarctic scientific community needs to make sure that the southern high latitudes continue to have a high profile in the discussions on the future of ocean drilling. There have been only 21 international expeditions or legs to the Southern Ocean since DSDP 21 in 1972 (excluding the shallow coring by USS Eltanin in the 1960s and campaigns by other nations). The Southern Ocean is by no means "done". The potential treasure troves of the Weddell Sea, Bellingshausen Sea and Amundsen Sea remain largely untouched, not to mention the extensive margin sequences of East Antarctica and the shelf areas of Australia and New Zealand. Drilling in the Southern Ocean is challenging, particularly in areas proximal to Antarctica, but no more so than the Arctic Ocean. There is still time - the consultation process is ongoing and the science plan is not yet complete.

The Antarctic and Southern Ocean research community needs to take a leaf out of the Arctic science community's book and develop a clear identity in making a case for southern high latitude ocean drilling. Ocean drilling is a proven and powerful tool for answering questions about the past that may help us to avoid some of the more unpleasant futures in prospect. We need to make sure that the potential of the Southern Ocean is fully recognized and acted upon in the next decade.

Alan P.M. Vaughan 